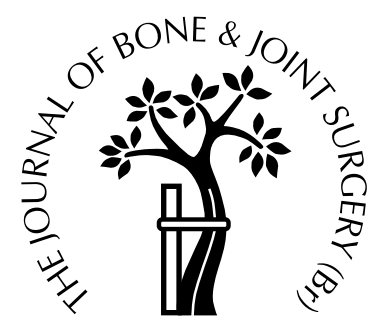

\title{
Annotation
}

\section{TOTAL KNEE ARTHROPLASTY IN PATIENTS WITH HAEMOPHILIA WHO ARE HIV-POSITIVE}

\author{
E. Carlos Rodriguez-Merchan
}

As a result of repeated episodes of articular bleeding from early childhood adult patients with haemophilia commonly have severe damage to the knee. They may present to the orthopaedic surgeon with pain and severe functional disability arising from advanced haemophilic arthropathy. ${ }^{1}$ There are many reports of successful operations on the knee in these patients including total knee arthroplasty (TKA) ${ }^{2-4}$ Further complications may arise in those who are also HIV-positive and there is controversy as to whether the benefits of TKA outweigh the higher level of risk.

Wiedel et al $^{5}$ described a series of 97 TKAs in 76 patients in which there was a progressive increase in acute infections, particularly in those who were HIV-positive. Similar problems were noted by Gregg-Smith et $\mathrm{al}^{6}$ who concluded that the high risk of secondary infection in HIV-positive patients was such that the procedure should only be carried out after careful selection. However, Birch et al $^{7}$ described 15 TKAs in haemophiliacs, eight of whom were HIVpositive. One of the latter became infected five years later after a dental extraction. The remainder were free from infection. These authors encouraged the use of TKA, emphasising that it did not increase the risk of postoperative infection. However, they noted that in patients with a low CD4 count, the HIV infection was likely to progress.

Löfqvist, Nilsson and Petersson ${ }^{8}$ reported six cases of TKA with only one of infection, in an HIV-positive patient who eventually required an arthrodesis. In 1997, Phillips et $\mathrm{al}^{9}$ assessed patients registered at a haemophilia centre between 1982 and 1994 to establish whether major orthopaedic surgical procedures accelerated the fall of CD4 lymphocyte counts in those who were HIV-positive, and whether those who underwent surgery had a different rate of development of AIDS or of earlier death compared with those who did not. A total of 61 surgical procedures was performed including 14 TKAs. They found no evidence to suggest that there was an acceleration in the rate of

E. Carlos Rodriguez-Merchan, MD, PhD, Consultant Orthopaedic Surgeon, Chairman of the Musculoskeletal Committee of the World Federation of Haemophilia

Haemophilia Centre, La Paz University Hospital, Capitan Blanco Argibay 21-G-3A, 28029 Madrid, Spain.

(C)2002 British Editorial Society of Bone and Joint Surgery

0301-620X/02/213015 \$2.00

J Bone Joint Surg [Br] 2002;84-B:170-2. decrease of CD4 lymphocytes in HIV-positive patients as a result of elective joint surgery. Neither the rate of development of AIDS nor mortality was affected. However, the authors expressed concern as to whether the general prognosis of HIV-related illness was adversely affected by the physiological demands of major surgery or any subsequent sepsis on an immune system which was already severely depleted.

Recently, Thomason et $\mathrm{al}^{10}$ published a report on 23 TKAs in 15 patients with a mean follow-up of 7.5 years and a minimum of four years for the eight patients who were alive at the time of their review. The seven patients who had died had been HIV-positive. Using the Hospital for Special Surgery knee scoring system, the result was excellent in one knee, good in three, fair in two and poor in 17. There were two cases of early and two of late deep infections, all in patients who were HIV-positive. One knee had to be revised for aseptic loosening.

A comprehensive, multicentre study by Ragni, Crossett and Herndon ${ }^{11}$ carried out in 115 centres in the USA found that the rate of postoperative infection in HIV-positive patients with haemophilia and CD4 counts of $<200 / \mathrm{mm}^{3}$ was higher than in those who did not have haemophilia. Of 27 TKAs, eight (30\%) became infected, compared with a rate of $1 \%$ to $2 \%$ in the normal population. They concluded that the decision to carry out total joint arthroplasty should only be taken after a thorough analysis of the risk-benefit ratio.

Rodriguez-Merchan and Wiedel ${ }^{12}$ carried out a retrospective review of 37 TKAs, performed on 26 men between March 1975 and November 1995. Seventeen were HIVpositive and nine were HIV-negative. HIV-positive patients were evaluated to assure a stable medical status. A CD4 count of $\geq 200 \mathrm{~mm}^{3}$ was considered to be appropriate for surgical treatment. Sixteen patients had previously had an arthroscopic or an open synovectomy. Overall, $22(84 \%)$ had good to excellent results, two $(8 \%)$ had fair and a further two (8\%) poor results as judged by the Hospital for Special Surgery knee score. The mean pain score improved from 11 to 28 after operation; a score of 30 indicated no pain. This showed the most dramatic improvement of all the categories. Knee function was graded on a scale with a maximum of 22 points; patients improved from a mean of 12 before to 17 after operation. 
Seventeen of these patients were HIV-positive, nine of whom have died from complications of acquired immunodeficiency disease. The mean survival time for HIV-positive patients was 9.6 years ( 3 to 16 ) after operation. These patients tolerated surgery well and there was no significant decline in the HIV rating.

Although the frequency of recurrent haemarthroses is usually much less in adults with advanced destructive changes, 16 of the 26 patients $(61 \%)$ reported a preoperative history of recurrent haemarthrosis ranging from one or two episodes per year to two or three per month. During hospital admission, the total amount of factor given ranged from 23500 to 111292 units per patient. After discharge, only three patients indicated that they experienced recurrent, infrequent haemarthroses and they responded well to administration of factor. However, two required a partial synovectomy to control frequent, recurrent episodes of bleeding which persisted after TKA. Overall, there were 28 complications in 37 joint replacements including haemarthrosis, arthrofibrosis, superficial wound infection, joint sepsis, wound dehiscence, palsy of the peroneal nerve and loosening of the prosthesis.

The complications after operation were subdivided into early or late. Severe haemarthrosis occurred in five patients (2/19 before 1986 and 3/18 after 1986); four were treated uneventfully by arthroscopic washout and one by open lavage. Two cases of partial palsy of the peroneal nerve were recognised in the immediate postoperative period but resolved satisfactorily. Failure to regain movement requiring manipulation under anaesthesia occurred in 12 patients (13/17 knees) before 1986, and in four (4/18 knees) after then. This may reflect the change to more aggressive factor replacement. Manipulation under anaesthesia was usually carried out within one to two weeks of the initial operation if flexion of more than $60^{\circ}$ to $70^{\circ}$ had not been obtained. One case of wound dehiscence occurred during this procedure.

Infection is the late complication of most concern. A superficial wound infection occurred in one patient and resolved after irrigation, debridement, and antibiotics. There were bilateral deep infections in two HIV-positive patients who had had CD4 counts of $<200 / \mathrm{mm}^{3}$ at the time of occurrence. The onset occurred two years after each respective TKA and in each there was a documented source of distant infection such as a dental abscess, sinusitis, or a contaminated needle. The first patient, who received a right cemented component in 1983 and a left uncemented component in 1986, developed a Pneumococcus infection in both knees in 1988. Initially, the bilateral knee infection responded to arthroscopic irrigation and parenteral antibiotics. However, in 1990, the patient had a Staphylococcus aureus infection of the right knee, and a two-stage salvage procedure was performed with a good result. Bilateral TKA was performed in the second patient in 1982, with the right side uncemented and the left side cemented. In 1984 and 1988, a Staphylococcus aureus infection occurred in both knees. Eventually, this patient underwent attempts at fusion which failed but left functional resection arthroplasties. Two knees were revised for loosening, one with progressive radiolucency at the bone-implant interface and the other with varus subsidence of the tibial component to approximately $20^{\circ}$. The index arthroplasties lasted for 11 and 12 years. Both were uncemented.

Recently, Hicks et $\mathrm{al}^{13}$ have published the results of 102 replacement arthroplasties in $73 \mathrm{HIV}$-positive patients from eight specialist centres. Of these, 91 were primary procedures. The overall rate of deep sepsis was $18.7 \%$ for primary procedures and $36.3 \%$ for revisions. There were 74 replacements of the knee. Between 1995 and 2000, I have performed ten TKAs in ten HIV-positive patients with haemophilia, all with a CD4 count greater than $200 / \mathrm{mm}^{3}$. No infections have appeared so far.

\section{Discussion}

Replacement arthroplasty of the knee has a high rate of complications with an excessive risk of postoperative infection, particularly in patients with haemophilia who are HIVpositive and have CD4 counts of $<200 / \mathrm{mm}^{3}$. Approximately $80 \%$ of haemophiliacs in developed countries are HIV-positive, mainly as a result of receiving contaminated factor concentrates in the early 1980s. In these patients TKA should only be considered in selected cases. Life expectancy, age and immunological status are paramount factors in the decision to proceed with a TKA in haemophilia. Although debridement should not be looked upon as an alternative, it should be considered in the young haemophiliac to avoid or delay TKA. Such a procedure may give the patient years of life without pain. When debridement fails, replacement must be considered.

In 1994 Rodriguez-Merchan, Magallon and Galindo ${ }^{14}$ described 11 open debridements in 11 patients suffering from advanced haemophiliac arthropathy of the knee who had been followed up for a mean of 5.4 years (2 to 11); the mean age of the patients was 28.7 years (25 to 42). The results were evaluated by the Hospital for Special Surgery disability score and were excellent in four, good in five and fair in two. A recent unpublished review shows that they remain the same at a mean follow-up of nine years (7 to 15). No debridement has yet required a TKA.

Theoretically, the alternative to TKA is an arthrodesis. Its main indications in haemophilia are for unilateral haemophiliac arthropathy in a young person without involvement of another joint in the limb, a painful knee which has had multiple operations, painful ankylosis and failed TKA; the last is the most frequent reason for fusion. Arthrodesis for failed septic knee replacement is indicated in the presence of persistent infection recalcitrant to repeated debridements and antibiotic regimes, disruption of the extensor mechanism because of infection, infection which is sensitive only to severely toxic antibiotic agents and in a young patient or a disillusioned older one who does not wish to face mul- 
tiple future revision arthroplasties. ${ }^{15}$ Fusion should be considered to be an irreversible procedure and should be performed selectively. Compression arthrodesis or intramedullary rod fixation can be used, each of which has a role in these difficult cases. So far, no arthrodesis has been performed on a patient with haemophilia at our centre.

The follow-up of published series of joint replacements is generally short. Ten years would be needed to confirm results although it can be expected that the rate of loosening and other complications will continue to increase.

The primary goals of TKA are to relieve pain, to restore function and to achieve stability. In chronic haemophiliac arthropathy the operation is technically demanding because of soft-tissue fibrosis, flexion contractures, and the poor quality of the bone. For these reasons, complications other than infection in HIV-negative haemophilia are more prevalent than in osteoarthritis. Moreover, if the patient is HIVpositive with a CD4 count of $<200 / \mathrm{mm}^{3}$, the risk of postoperative infection after TKA can reach up to $30 \%$.

The large study of Hicks et $\mathrm{al}^{13}$ has confirmed the high rates of infection after TKA, but it is pointed out that most patients already diagnosed with HIV infection at the time of surgery should derive many years of symptomatic relief after a successful joint replacement. ${ }^{11,12}$ Therefore, careful counselling and education of both patients and healthcare workers before operation are essential. ${ }^{12,13}$

\section{Conclusion}

In the era of total joint replacement a TKA should be indicated in HIV-positive patients with haemophilia who have severe pain in the knee and disability. However, the high risk of infection and other postoperative complications is a concern. Although the message of this annotation may seem to be conservative, it should not be inferred that a TKA should be avoided in a HIV-positive patient with haemophilia but that the orthopaedic surgeon should weigh the risks and benefits. ${ }^{12} \mathrm{~A}$ careful and conservative approach is needed. However, recent improvements in medical treatment can diminish the previously reported rate of postoperative infection and give grounds for continued optimism.

\section{References}

1. Rodriguez-Merchan EC. Management of the orthopaedic complications of haemophilia. J Bone Joint Surg [Br] 1998;80-B:191-6.

2. Lachiewicz PF, Inglis AE, Insall JN, et al. Total knee arthroplasty in hemophilia. J Bone Joint Surg [Am] 1985;67-A:1361-6.

3. Figgie MP, Goldberg VM, Figgie HE, Heiple KG, Sobel M. Total knee arthroplasty for the treatment of chronic hemophilic arthropathy. Clin Orthop 1989;248:98-107.

4. Karthaus RP, Novakova IRO. Total knee replacement in haemophilic arthropathy. J Bone Joint Surg [Br] 1988;70-B:382-5.

5. Wiedel JD, Luck JV, Gilbert MS. Total knee arthroplasty in the patient with hemophilia: evaluation and long-term results. In: Gilbert MS, Greene WB, eds. Musculoskeletal problems in hemophilia. National Hemophilia Foundation, 1989:152-7.

6. Gregg-Smith SJ, Pattison RM, Dodd CAF, Giangrande PLF, Duthie RB. Septic arthritis in haemophilia. J Bone Joint Surg [Br] 1993;75-B:368-70.

7. Birch NC, Ribbans WJ, Goldman E, Lee CA. Knee replacement in haemophilia. J Bone Joint Surg [Br] 1994;76-B:165-6.

8. Löfqvist T, Nilsson IM, Petersson C. Orthopaedic surgery in haemophilia: 20 years' experience in Sweden. Clin Orthop 1996;332:232-41.

9. Phillips AM, Sabin CA, Ribbans WJ, Lee CA. Orthopaedic surgery in hemophilic patients with human immunodeficiency virus. Clin Orthop 1997;343:81-7.

10. Thomason HC 3rd, Wilson FC, Lachiewicz PF, Kelley SS. Knee arthroplasty in hemophilic arthropathy. Clin Orthop 1999;360:169-73.

11. Ragni MV, Crossett LS, Herndon JH. Postoperative infection following orthopaedic surgery in human immunodefiçiency virus-infected hemophiliacs with CD4 counts $<200 / \mathrm{mm}^{3}$. J Arthroplasty 1995;10:716-21.

12. Rodriguez-Merchan EC, Wiedel JD. Total knee arthroplasty. In: Rodriguez-Merchan EC, Goddard NJ, Lee CA, eds. Musculoskeletal aspects of haemophilia. Oxford, etc: Blackwell, 2000:78-84.

13. Hicks JL, Ribbans WJ, Buzzard B, et al. Infected joint replacements in HIV-positive patients with haemophilia. J Bone Joint Surg [Br] 2001;83-B:1050-4.

14. Rodriguez-Merhan EC, Magallon M, Galindo E. Joint debridement for haemophilic arthropathy of the knee. Int Orthop 1994;18:135-8.

15. Windsor RE, Bono JV. Arthrodesis and resection arthroplasty. In: Fu FH, Harner CD, Vince KG, eds. Knee Surgery. Vol. 2. Baltimore, etc: William \& Wilkins, 1994:1587-95. 